Original article

Red Beetroot Thematic Issue

\title{
Profile of Phenolic Acids and Flavonoids of Red Beet and Its Fermentation Products. Does Long-Term Consumption of Fermented Beetroot Juice Affect Phenolics Profile in Human Blood Plasma and Urine?
}

\author{
Natalia Ptatosz ${ }^{1 *}$,Tomasz Sawicki ${ }^{1,2}$, Wiesław Wiczkowski ${ }^{1}$ \\ 'Department of Chemistry and Biodynamics of Food, Division of Food Science, \\ Institute of Animal Reproduction and Food Research of Polish Academy of Sciences, Tuwima 10, 10-748 Olsztyn, Poland \\ ${ }^{2}$ Department of Human Nutrition, Faculty of Food Science, \\ University of Warmia and Mazury in Olsztyn, Sloneczna 45f, 10-718 Olsztyn, Poland
}

Key words: phenolic acids, flavonoids, red beet, fermentation, consumption, human body fluids profile

The aim of this study was to determine the profile of phenolic acids and flavonoids in red beetroot products and these compounds fate in the human body after long-term exposure to fermented red beet juice. Phenolic acids and flavonoids were analyzed by HPLC-MS/MS. The performed analysis revealed that beetroot and its products were the notable sources of phenolic acids and flavonoids, with isoferulic acid, protocatechuic acid, epicatechin, and apigenin predominating among the twenty compounds detected. However, the compounds analyzed appeared mainly in the bound form in the fresh material. The results obtained indicate that the fermentation process caused an increase in the content of free phenolic acids and reduced the content of conjugated phenolic acids. Contrarily to phenolic acids, the same process caused a reduction in the content of free flavonoids and an increase in the content of conjugated flavonoids. Moreover, the 14-day spontaneous fermentation process resulted in a significant reduction (by $45.18 \%$ ) in the total content of phenolics (phenolic acids and flavonoids). However, it was observed that forty-two days of the regular intake of the fermented beetroot juice $(200 \mathrm{~mL} / 60 \mathrm{~kg}$ body weight) generally did not affect concentrations of phenolic acids and flavonoids in the volunteers' body fluids compared to their concentrations in fluids before fermented beetroot juice consumption.

\section{INTRODUCTION}

Red beetroot (Beta vulgaris L. subsp. vulgaris) is a great source of minerals (such as manganese, iron, potassium, magnesium, and cobalt), vitamins $\mathrm{B}$ and $\mathrm{C}$ as well as a number of bioactive substances such as polyphenols, carotenoids, nitrate, and betalains. Due to the high contents of these phytochemicals, beetroot is in the top of ten vegetables with the most powerful antioxidant influence [Carrillo et al., 2017; Raikos et al., 2016]. Additionally, these features may determine the other biological aspects of beetroots. It has been suggested that red beet has anti-neurodegenerative, antitumor, anti-inflammatory, antibacterial, antiviral, cardioprotective, and lipid peroxidation inhibitory activities [Clifford et al., 2015]. For these reasons, consuming red beetroot might have beneficial effects on human and animal organisms.

Beetroot is eaten fresh and after cooking. In addition, this raw material is used in the processing industry for the production of drinking and concentrated juices, frozen foods, dried fruit, lyophilizate, and for the production of natural red dyes [Chhikara et al., 2019]. One of the technological processes used in the food industry is fermentation, which involves

\footnotetext{
* Corresponding Author: Tel.: +48 895234631

E-mail: n.platosz@pan.olsztyn.pl (N. Płatosz)
}

the use of transformations occurring under the influence of enzymes produced by yeast and bacteria. During the fermentation process, in addition to basic end products, additional nutrients are produced and toxins removed. What is more, lactic acid bacteria found in all non-heat treated fermented foods have a positive effect on digestive health [Hasan et al., 2014]. It is so important, therefore, to determine to what extent an applied technological process affects the profile and content of biologically active compounds of vegetables and fruits.

Phenolics compounds, which include flavonoids and phenolic acids, are very important secondary metabolites of plants and have highly varied structures and properties. In addition, numerous studies point to their strong antioxidant activities [Saxena et al., 2012]. Moreover, long-term consumption of diets rich in biologically active polyphenols provides protection against the development and progression of lifestyle diseases such as cardio- and cerebrovascular diseases, cancer, diabetes or neurodegenerative diseases [Pandey \& Rizvi, 2009]. Previous studies have indicated the absorption of phenolic acids and flavonoids by animal and human organisms and the occurrence of native and conjugated forms in their body fluids [Wiczkowski et al., 2008]. It should be noted, however, that the consumption of bioactive foods is not synonymous with good bioavailability and the potentially protective effect on the human body. To verify whether bioactive compounds can have a positive effect on the human body, 
at first should be determined the bioavailability and structure of the compounds that occur in the body fluids after the consumption of foods rich in bioactive substances [Rein et al., 2013]. In this context, the aim of this study was to analyze the profile and content of red beetroot phenolics (phenolics acids and flavonoids) in red beetroot products (fresh roots, fermented roots, and commercial fermented red beet juice) and whether the long-term and regular consumption of red beetroot affects the profile and concentration of phenolics in blood plasma and urine of volunteers.

\section{MATERIALS AND METHODS}

\section{Chemicals and reagents}

Water, methanol, acetonitrile, formic acid, and diethyl ether were purchased from Sigma Chemical Co. (St. Louis, MO, USA). Protocatechuic acid, $m$-hydroxybenzoic acid, chlorogenic acid, caffeic acid, syringic acid, sinapic acid, ferulic acid, isoferulic acid, $p$-coumaric acid, $p$-hydroxybenzoic acid, 3,4-dihydroxyphenylacetic acid, trans-cinnamic acid, vitexin, rutin, epicatechin, luteolin, quercetin, apigenin, kaempferol, and orientin were purchased from Sigma Chemical Co. (St. Louis, MO, USA) and Extrasynthese (Genay, France).

\section{Research materials and processes}

Healthy red beetroots $(3 \mathrm{~kg})$, with no signs of mechanical damage, were acquired from the local market in Olsztyn (Poland). Next, the roots were cleaned, mixed, and divided into two groups: fresh roots and roots for the fermentation process. Commercially fermented red beetroot juice was obtained from Zakład Przetwórstwa Owocowo-Warzywnego VITAPOL Sp. J. M. T. Ciszkiewicz, Podkowa Leśna, Poland (Eng. Fruit and Vegetable Processing Plant VITAPOL Sp. J. M. T. Ciszkiewicz).

\section{Fresh roots}

The red beetroots assigned to the fresh group (1.5 kg) were cut into four parts, then two opposite quarters were frozen at $-80^{\circ} \mathrm{C}$, lyophilized, pulverized, and stored at $-80^{\circ} \mathrm{C}$ until analysis of the profile and content of phenolic acids and flavonoids.

\section{Fermentation process}

The spontaneous fermentation process was conducted according to the method described by Sawicki \& Wiczkowski [2018]. Briefly, the whole roots (1.5 kg) were cut into 2-3 mm thick slices. Then, the root slices were placed in a stoneware dish and submerged in a properly prepared marinade (1.5 L water, $12 \mathrm{~g}$ salt, and $12 \mathrm{~g}$ sugar). The materials obtained were thoroughly mixed, and three independent fermentations were started. The process was carried out over two weeks in the dark at a constant temperature of $23^{\circ} \mathrm{C}$ until the $\mathrm{pH}$ stabilized. The $\mathrm{pH}$ was measured once a day using a pH-meter PHM85 (Radiometer, Copenhagen, Denmark), and the $\mathrm{pH}$ values obtained, ranging from $7.02 \pm 0.02$ (fresh juice) to $3.63 \pm 0.012$ (after a 14-day fermentation process), clearly showed that the process was conducted properly. After 14 days, the spontaneous fermentation process ended, and the fermented red beetroots ( $200 \mathrm{~g}$ ) were collected from each stoneware pot and frozen. Next, the roots were lyophilized, pulverized, and stored at $-80^{\circ} \mathrm{C}$ until analysis.

\section{Subjects and study design}

Samples of blood plasma and urine were obtained from volunteers who participated in a 42-day non-clinical medical study with an experimental diet. The study was led in accordance with the ethical principles of the Declaration of Helsinki, and the study protocol was accepted by the Bioethical Committee at the Faculty of Medical Science of the University of Warmia and Mazury in Olsztyn (Poland, No. 7/2015). All volunteers were fully informed about the study and signed an informed consent form. Moreover, the study was carried out in the NZOZ Atarax Clinic in Olsztyn, Poland under medical supervision.

Men (5) and women (19) between 24 and 40 years of age participated in the experiment. Inclusion criteria were as follows: they had to be certified healthy at a medical interview, have a body mass index (BMI) under 30, and have no gastrointestinal disturbances, including gastric and duodenal ulcers; they could not participate in other clinical trials within 90 days prior to the survey, take drugs, abuse alcohol, be pregnant and breast-feeding, or take any medications or vitamin supplements.

During the 7 days before starting the experimental diet, the volunteers followed their everyday diet while excluding all products obtained from red beet (red beets, strawberry yogurt, strawberry ice cream, fruit juice, wine, and other products containing E162 dye) to eliminate the main compounds within their systems originating from this vegetable. Then, for 42 days, once a day, directly after breakfast, the volunteers drunk a dose of the fermented beetroot juice $(200 \mathrm{~mL} / 60 \mathrm{~kg}$ body weight). All volunteers included in the study visited NZOZ Atarax every 7 days to have their health status evaluated and to receive the juice of fermented beetroot for the next 7 days. Under fasting conditions, before consumption (sample zero) and after 7, 21, and 42 days of daily consumption of fermented beet juice, elbow or forearm vein blood samples were taken in heparinized vacutainers, and the blood obtained was centrifuged $\left(500 \times g, 15 \mathrm{~min}, 1000 \times g, 10 \mathrm{~min}, 4^{\circ} \mathrm{C}, \mathrm{MPW}-351 \mathrm{R}\right.$ Centrifuge, MPW-Med. Instruments, Warsaw, Poland). In addition, according to the above sampling scheme $(0,7,21$, and 42 days), urine samples were collected from the volunteers. Thereafter, the separated plasma and collected urine were frozen and stored at $-80^{\circ} \mathrm{C}$ until analysis.

\section{Extraction of free forms of phenolic acids and flavonoids}

The profile and content of phenolic acids and flavonoids were analyzed according to the method described by Wiczkowski et al. [2016], with some modifications. Extracts from fresh and fermented red beetroots were prepared. About $0.15 \mathrm{~g}$ of each solid sample were extracted with $1 \mathrm{~mL}$ of a mixture of methanol/water/formic acid $(80 / 19.9 / 0.1 ; v / v / v)$ by stirring overnight (about $24 \mathrm{~h}$ ) at $10^{\circ} \mathrm{C}$ using a ThermoMixer (Benchmark Scientific, Saryeville, NJ, USA). The solutions were centrifuged $\left(13,200 \times g, 20 \mathrm{~min}, 4^{\circ} \mathrm{C}\right.$, Centrifuge 5415R, Eppendorf, Hamburg, Germany) and the supernatants were combined into 1-mL volumetric flask. The volume was brought up to $1 \mathrm{~mL}$ with distilled water. The obtained extracts were stored at $-80^{\circ} \mathrm{C}$ until analysis. 
For HPLC-MS/MS analysis, extracts from fresh and fermented red roots as well as fermented red beetroot juices, blood plasma and urine were prepared according to the following procedure: samples of fresh $(100 \mu \mathrm{L})$, fermented red roots $(100 \mu \mathrm{L})$, commercial fermented juice $(100 \mu \mathrm{L})$, blood plasma $(200 \mu \mathrm{L})$, and urine $(100 \mu \mathrm{L})$ were transferred to $15-\mathrm{mL}$ glass test-tubes and next evaporated to dryness under a nitrogen atmosphere at $30^{\circ} \mathrm{C}$. The sediments obtained were dissolved in $400 \mu \mathrm{L}$ of distilled water, acidified to $\mathrm{pH} 2$, were extracted by vortexing (60 s) and sonication (60 s). Next, the free forms of phenolic acids and flavonoids were extracted three times with $2 \mathrm{~mL}$ of diethyl ether by vortexing (60 s) and sonication (60 s) (VC 750, Sonics \& Materials Inc., Newtown, CT, USA). After centrifugation for $10 \mathrm{~min}(3,000 \times \mathrm{g}$, $4^{\circ} \mathrm{C}$, Centrifuge, Beckman, Indianapolis, IN, USA) the separated ether layer was collected and evaporated to dryness with a stream of nitrogen at $30^{\circ} \mathrm{C}$. The extraction procedure with diethyl ether was repeated three times and the organic layers were combined. The dried samples were stored at $-80^{\circ} \mathrm{C}$ until analysis. The remaining aqueous extracts were left for about 10 min under nitrogen to remove residual diethyl ether and then stored in sealed test tubes at $4^{\circ} \mathrm{C}$ until the extraction of phenolic acids and flavonoids released from soluble esters.

\section{Extraction of phenolic acids and flavonoids released from soluble esters}

Next, $1 \mathrm{~mL}$ of $4 \mathrm{M} \mathrm{NaOH}$ was added to the aqueous extracts remaining from the extraction of free forms of phenolic acids and flavonoids. The mixture was placed in a nitrogen atmosphere and hydrolyzed for $4 \mathrm{~h}$ at room temperature using a magnetic stirrer. The solutions were then adjusted to pH 2 with $6 \mathrm{M} \mathrm{HCl}$. Liberated phenolic acids and flavonoids were extracted three times with $2 \mathrm{~mL}$ of diethyl ether by vortexing $(60 \mathrm{~s})$ and sonication $(60 \mathrm{~s})$, and then centrifuged $\left(3,000 \times g\right.$ at $\left.4^{\circ} \mathrm{C}, 10 \mathrm{~min}\right)$. The organic layers were collected, combined, and evaporated to dryness with a stream of nitrogen at $30^{\circ} \mathrm{C}$. The remaining aqueous extracts were left for about 10 min under nitrogen to remove residual diethyl ether and then were stored in closed tubes at $4^{\circ} \mathrm{C}$ until the extraction of phenolic acids and flavonoids released from soluble glycosides.

\section{Extraction of phenolic acids and flavonoids released from soluble glycosides}

After alkaline hydrolysis, acid hydrolysis was performed by adding $0.2 \mathrm{~mL}$ of $6 \mathrm{M} \mathrm{HCl}$ into the test tube and incubation in a Heat Block (Benchmark Scientific, Saryeville, NJ, USA) at $100^{\circ} \mathrm{C}$ for $60 \mathrm{~min}$. Next, the samples were cooled, adjusted to $\mathrm{pH} 2$ with $8 \mathrm{M} \mathrm{NaOH}$, and handled in the same manner as after alkaline hydrolysis.

\section{Chromatographic analysis}

The dry residues containing free phenolic compounds, as well as the compounds released from ester and glycosidic bonds (fresh and fermented red roots, commercial fermented juice, blood plasma, and urine) were dissolved in $100 \mu \mathrm{L}$ of $80 \%(\mathrm{v} / \mathrm{v})$ methanol containing $0.95 \%(\mathrm{v} / \mathrm{v})$ formic acid, centrifuged $\left(13,200 \times g\right.$ at $\left.4^{\circ} \mathrm{C}, 20 \mathrm{~min}\right)$, and analyzed by using the HPLC system (LC-200, Eksigent, Vanghan, ON,
TABLE 1. Phenolic acids and flavonoids identified in fresh and fermented beetroot, commercial fermented red beet juice, as well as in blood plasma and urine of the volunteers.

\begin{tabular}{|c|c|c|c|c|c|}
\hline No & Compounds & \begin{tabular}{|c|}
$R_{t}$ \\
$(\mathrm{~min})$
\end{tabular} & $\begin{array}{l}{[\mathrm{M}]^{-}} \\
(\mathrm{m} / \mathrm{z}) \\
\end{array}$ & $\begin{array}{c}\mathrm{MS} / \mathrm{MS} \\
(\mathrm{m} / \mathrm{z})\end{array}$ & Sample \\
\hline \multicolumn{6}{|c|}{ Phenolic acids } \\
\hline 1 & Protocatechuic acid & 0.94 & 153 & $91 / 81$ & $\begin{array}{c}\text { B, F, J, } \\
\text { P, U }\end{array}$ \\
\hline 2 & $m$-Hydroxybenzoic acid & 0.99 & 137 & $93 / 65$ & $\begin{array}{l}\text { B, F, J, } \\
\text { P, U }\end{array}$ \\
\hline 3 & Chlorogenic acid & 1.00 & 353 & $191 / 179$ & $\begin{array}{l}\mathrm{B}, \mathrm{F}, \mathrm{J}, \\
\mathrm{P}, \mathrm{U}\end{array}$ \\
\hline 4 & Caffeic acid & 1.04 & 179 & $135 / 107$ & $\begin{array}{l}\text { B, F, J, } \\
\text { P, U }\end{array}$ \\
\hline 5 & Syringic acid & 1.06 & 197 & $182 / 153$ & $\begin{array}{l}\text { B, F, J, } \\
\text { P, U }\end{array}$ \\
\hline 6 & Sinapic acid & 1.13 & 223 & $208 / 179 / 164$ & $\begin{array}{c}\text { B, F, J, } \\
\text { P, U }\end{array}$ \\
\hline 7 & Ferulic acid & 1.15 & 193 & $178 / 134$ & $\begin{array}{l}\mathrm{B}, \mathrm{F}, \mathrm{J}, \\
\mathrm{P}, \mathrm{U}\end{array}$ \\
\hline 8 & Isoferulic acid & 1.20 & 193 & $178 / 134$ & $\mathrm{~B}, \mathrm{~F}, \mathrm{~J}$, \\
\hline 9 & $p$-Coumaric acid & 1.22 & 163 & $119 / 93$ & $\begin{array}{l}\text { B, F, J, } \\
\text { P, U }\end{array}$ \\
\hline 10 & p-Hydroxybenzoic acid & 1.28 & 137 & 98/93 & $\begin{array}{l}\text { B, F, J, } \\
\text { P, U }\end{array}$ \\
\hline 11 & $\begin{array}{l}\text { 3,4-Dihydroxyphenylacetic } \\
\text { acid }\end{array}$ & 1.30 & 169 & $125 / 109 / 95$ & $\begin{array}{c}\text { B, F, J, } \\
\text { P, U }\end{array}$ \\
\hline 12 & trans-Cinnamic acid & 1.35 & 147 & $119 / 109 / 103$ & $\begin{array}{c}\mathrm{B}, \mathrm{F}, \mathrm{J}, \\
\mathrm{P}, \mathrm{U}\end{array}$ \\
\hline \multicolumn{6}{|c|}{ Flavonoids } \\
\hline 13 & Vitexin & 1.00 & 431 & $323 / 311 / 283$ & $\mathrm{~B}, \mathrm{~F}, \mathrm{~J}$ \\
\hline 14 & Rutin & 1.02 & 609 & $463 / 301$ & $\mathrm{~B}, \mathrm{~F}, \mathrm{~J}$ \\
\hline 15 & Epicatechin & 1.04 & 289 & $245 / 203 / 109$ & $\begin{array}{l}\text { B, F, J, } \\
\text { P, U }\end{array}$ \\
\hline 16 & Luteolin & 1.26 & 285 & $151 / 133$ & $\begin{array}{l}\text { B, F, J, } \\
\text { P, U }\end{array}$ \\
\hline 17 & Quercetin & 1.27 & 301 & $179 / 151$ & $\begin{array}{l}\mathrm{B}, \mathrm{F}, \mathrm{J}, \\
\mathrm{P}, \mathrm{U}\end{array}$ \\
\hline 18 & Apigenin & 1.33 & 269 & $225 / 151 / 117$ & $\begin{array}{l}\text { B, F, J, } \\
\text { P, U }\end{array}$ \\
\hline 19 & Kaempferol & 1.35 & 285 & $185 / 93$ & $\begin{array}{l}\mathrm{B}, \mathrm{F}, \mathrm{J} \\
\mathrm{P}, \mathrm{U}\end{array}$ \\
\hline 20 & Orientin & 1.95 & 447 & $357 / 339 / 296$ & $\mathrm{~B}, \mathrm{~F}, \mathrm{~J}$ \\
\hline
\end{tabular}

$\mathrm{R}$ - retention time; $\mathrm{B}$ - fresh beetroot; F - fermented beetroot; J - commercial fermented red beet juice; $\mathrm{P}$ - blood plasma; $\mathrm{U}$ - urine.

Canada) coupled with a mass spectrometer (QTRAP 5500, AB Sciex, Vaughan, ON, Canada) consisting of a triple quadrupole, ion trap, and ion source of electrospray ionization (ESI). The chromatographic separation was conducted with an HALO $\mathrm{C}_{18}$ column $(50 \mathrm{~mm} \times 0.5 \mathrm{~mm} \times 2.7 \mu \mathrm{m}$, Eksigent, Vaughan, ON, Canada) at $45^{\circ} \mathrm{C}$, at the flow rate of $15 \mu \mathrm{L} / \mathrm{min}$. The elution was conducted using a solvent gradient system consisting of solvent A $(0.9 \%(\mathrm{v} / \mathrm{v})$ formic acid aqueous solution) and solvent B $(0.9 \%(v / v)$ formic acid acetonitrile solution). The gradient used was as follows: $0.5 \% \mathrm{~B}$ for $0.5 \mathrm{~min}, 0.5-90 \% \mathrm{~B}$ in $1.5 \mathrm{~min}, 90 \% \mathrm{~B}$ for $0.5 \mathrm{~min}, 90-0.5 \%$ $\mathrm{B}$ in $0.2 \mathrm{~min}$, and $0.5 \% \mathrm{~B}$ for $0.3 \mathrm{~min}$. An optimal identification of the analyzed phenolic acids and flavonoids was achieved 
under the following ESI-MS/MS conditions: negative ionization, curtain gas: $20 \mathrm{~L} / \mathrm{min}$, collision gas: ion spray voltage: $5300 \mathrm{~V}$, temperature: $350^{\circ} \mathrm{C}, 1$ ion source gas: $35 \mathrm{~L} / \mathrm{min}, 2$ ion source gas: $30 \mathrm{~L} / \mathrm{min}$, declastering potential: $100 \mathrm{~V}$, entrance potential: $10 \mathrm{~V}$, collision energy: $40 \mathrm{eV}$, and collision cell exit potential: $20 \mathrm{~V}$. Identification and quantitation of the phenolic acids and flavonoids were based on the comparison of their retention times and the presence of the respective parent and daughter ion pairs (Multiple Reaction Monitoring method, MRM) (Table 1) with data obtained after analysis of the authentic standards. The external standards $(0.01-$ $-0.5 \mu \mathrm{g} / \mathrm{mL}$ ) had linear calibration curves with a coefficient of determination of $0.997-0.999$. The concentrations of individual phenolics were expressed as concentrations of their free and conjugated forms (a sum of phenolics released from ester and glycosidic bonds) of phenolic acids or flavonoids. The results were expressed in $\mu \mathrm{g} / \mathrm{g}$ dry matter $(\mathrm{dm})$ of fresh and fermented red beetroot, and in $\mu \mathrm{g} / \mathrm{mL}$ of red beetroot juice, blood plasma, and urine. All analyses were performed in triplicate for each sample.

\section{Statistical analyses}

The data are presented as the mean \pm the standard deviation (SD). Statistical differences among the samples were tested using one-way ANOVA with the Tukey's test. Differences were considered significant at $\mathrm{P}<0.05$. The statistical analysis was performed using the Statistica software (Stat Soft, Tulsa, OK, USA).

\section{RESULTS AND DISCUSSION}

\section{Profile and content of phenolic acids and flavonoids in red beet products}

In the fresh and fermented red beetroots as well as in the commercial fermented red beet juices, twelve phenolic acids were found (Table 1). Four of the identified phenolic acids were hydroxybenzoic acid derivatives (protocatechuic, $m$-hydroxybenzoic, syringic, and $p$-hydroxybenzoic acids), while seven phenolic acids belonged to the hydroxycinnamic acid derivative classification (chlorogenic, caffeic, sinapic, ferulic, isoferulic, $p$-coumaric, and trans-cinnamic acids), and one phenylacetic acid derivative (3,4-dihydroxyphenylacetic acid) was detected as well. Previously published data have also shown the presence of derivatives of hydroxybenzoic acid (protocatechuic acid, $p$-hydroxybenzoic acid, syringic acid, vanillic acid) and hydroxycinnamic acid (chlorogenic acid, caffeic acid, ferulic acid, coumaric acid, cinnamic acid) in red beetroot products [Mattila \& Hellström, 2007; Georgiev et al., 2010; Ravichandran et al., 2012; Vulić et al., 2014; Ben Haj Koubaier et al., 2014; Székely et al., 2014; Wruss et al., 2015; Değirmencioğlu et al., 2016]. To the best of our knowledge, our study is the first to show the full profile of phenolic acids in red beetroot products. Moreover, this is the first study that identifies phenylacetic acid derivative in these products.

The main compound among the phenolic acids in the fresh and fermented red beetroot analyzed was isoferulic acid (88.9\% and $61.9 \%$ of the total phenolic acids, respectively) (Table 2). Furthermore, in the fresh roots, the second most dominant compound was syringic acid, followed by ferulic, $p$-coumaric, and sinapic acids. On the other hand, in fermented beetroot, the second major compound was protocatechuic acid, followed by sinapic, ferulic, caffeic, and $p$-coumaric acids. Interestingly, in contrast to the fresh and fermented red beetroot, the main compound detected in the commercial fermented red beetroot juice was protocatechuic acid. Its total content was at $0.979 \mu \mathrm{g} / \mathrm{mL}$ (30.7\% of the total phenolic acids in the fermented red beetroot juice). In addition, trans-cinnamic acid was the second major compound, followed by isoferulic, $p$-hydroxybenzoic, $m$-hydroxybenzoic, syringic, and sinapic acids (Table 2). Interestingly, the results we obtained are significantly different from those available in the literature. The available data show that the major phenolic acids in solid red beetroot were $p$-hydroxybenzoic acid [Ravichandran et al., 2012], caffeic acid [Georgiev et al., 2010], and vanillic acid [Ben Haj Koubaier et al., 2014]. On the other hand, in liquid red beet products, the dominant compound was gallic acid (fresh juice) [Wruss et al., 2015], while in fermented juice, the main detected acid was vanillic acid [Değirmencioğlu et al., 2016].

The results of the study showed that the fermentation process resulted in a change in phenolic acid content. In our research, contents of the hydroxybenzoic acid derivatives (protocatechuic, $m$-hydroxybenzoic, syringic, and $p$-hydroxybenzoic acids) and hydroxycinnamic acid derivatives (chlorogenic, caffeic, sinapic, ferulic, isoferulic, $p$-coumaric, and trans-cinnamic acids) in the fresh roots were at $1.55 \pm 0.00 \mu \mathrm{g} / \mathrm{g} \mathrm{dm}$ and $30.66 \pm 0.00 \mu \mathrm{g} / \mathrm{g} \mathrm{dm}$, respectively. However, the content of the detected phenylacetic acid derivative (3,4-dihydroxyphenylacetic acid) in fresh roots approximated the limit of detection. As in the case of fresh beetroot, in fermented red beetroot, the content of hydroxycinnamic acid derivatives was much higher $(14.22 \pm 0.01 \mu \mathrm{g} / \mathrm{g} \mathrm{dm})$ than of the hydroxybenzoic acid derivatives $(3.27 \pm 0.00 \mu \mathrm{g} / \mathrm{g} \mathrm{dm})$. In general, phenolic acids in fresh, as well as in fermented beetroot, appeared mostly in bound forms $(31.79 \pm 0.01 \mu \mathrm{g} / \mathrm{g}$ $\mathrm{dm}$ and $16.40 \pm 0.01 \mu \mathrm{g} / \mathrm{g} \mathrm{dm})$ compared with the presence the free forms $(0.42 \pm 0.00 \mu \mathrm{g} / \mathrm{g} \mathrm{dm}$ and $1.11 \pm 0.00 \mu \mathrm{g} / \mathrm{g} \mathrm{dm}$, respectively). It is important to note that the fermentation process resulted in a 2.64-fold increase in the content of free phenolic acids, including: sinapic, isoferulic, $p$-coumaric, $p$-hydroxybenzoic, and trans-cinnamic acids, but caused no changes in the proportion of free protocatechuic, $m$-hydroxybenzoic, chlorogenic, syringic, and 3,4-dihydroxyphenylacetic acids. A decrease in the proportion of the free forms after the fermentation treatment was observed only in the case of ferulic acid. The fermentation of red beetroots affected also contents of the bound forms of phenolic acids. The process applied increased the proportion of the conjugated protocatechuic, $m$-hydroxybenzoic, chlorogenic, caffeic, sinapic, ferulic, $p$-coumaric, $p$-hydroxybenzoic, and 3,4-dihydroxyphenylacetic acids (Table 2). Chlorogenic and 3,4-dihydroxyphenylacetic acids in fresh beetroot roots were at the limit of detection. In fermented roots, chlorogenic acid accounted for only $0.1 \%$ of total phenolic acids and was found only in the bound form (after alkaline and acid hydrolysis). The low level of chlorogenic acid and detection of this compound after hydrolysis may be due to the fact that chlorogenic acid occurs in the larger structures (polysaccharides, lignins) in the red 
TABLE 2. Content and contribution of phenolic acids and flavonoids in red beet products.

\begin{tabular}{|c|c|c|c|c|c|c|c|c|}
\hline \multirow{3}{*}{ No } & \multirow{3}{*}{ Compounds } & \multirow{3}{*}{ Form } & \multicolumn{6}{|c|}{ Red beet products } \\
\hline & & & \multicolumn{2}{|c|}{ Fresh } & \multicolumn{2}{|c|}{ Fermented } & \multicolumn{2}{|c|}{ Commercial juice } \\
\hline & & & $\mu \mathrm{g} / \mathrm{g} \mathrm{dm}$ & $\%$ & $\mu \mathrm{g} / \mathrm{g} \mathrm{dm}$ & $\%$ & $\mu \mathrm{g} / \mathrm{mL}$ & $\%$ \\
\hline \multicolumn{9}{|c|}{ Phenolic acids } \\
\hline \multirow{2}{*}{1} & \multirow{2}{*}{ Protocatechuic acid } & $\mathrm{F}$ & 0.000 & 0.0 & 0.000 & 0.0 & 0.016 & 0.5 \\
\hline & & $\mathrm{C}$ & 0.258 & 0.8 & 2.644 & 15.1 & 0.963 & 30.2 \\
\hline \multirow{2}{*}{2} & \multirow{2}{*}{$m$-hydroxybenzoic acid } & $\mathrm{F}$ & 0.000 & 0.0 & 0.000 & 0.0 & 0.029 & 0.9 \\
\hline & & $\mathrm{C}$ & 0.097 & 0.3 & 0.070 & 0.4 & 0.144 & 4.5 \\
\hline \multirow{2}{*}{3} & \multirow{2}{*}{ Chlorogenic acid } & $\mathrm{F}$ & 0.000 & 0.0 & 0.000 & 0.0 & 0.003 & 0.1 \\
\hline & & $\mathrm{C}$ & 0.000 & 0.0 & 0.018 & 0.1 & 0.022 & 0.7 \\
\hline \multirow{2}{*}{4} & \multirow{2}{*}{ Caffeic acid } & $\mathrm{F}$ & 0.000 & 0.0 & 0.525 & 3.0 & 0.016 & 0.5 \\
\hline & & $\mathrm{C}$ & 0.258 & 0.8 & 0.263 & 1.5 & 0.185 & 5.8 \\
\hline \multirow{2}{*}{5} & \multirow{2}{*}{ Syringic acid } & $\mathrm{F}$ & 0.000 & 0.0 & 0.000 & 0.0 & 0.041 & 1.3 \\
\hline & & $\mathrm{C}$ & 0.934 & 2.9 & 0.263 & 1.5 & 0.102 & 3.2 \\
\hline \multirow{2}{*}{6} & \multirow{2}{*}{ Sinapic acid } & $\mathrm{F}$ & 0.000 & 0.0 & 0.018 & 0.1 & 0.003 & 0.1 \\
\hline & & $\mathrm{C}$ & 0.387 & 1.2 & 1.033 & 5.9 & 0.096 & 3.0 \\
\hline \multirow{2}{*}{7} & Eerulic neid & $\mathrm{F}$ & 0.193 & 0.6 & 0.018 & 0.1 & 0.041 & 1.3 \\
\hline & reruinc acid & $\mathrm{C}$ & 0.612 & 1.9 & 1.016 & 5.8 & 0.045 & 1.4 \\
\hline 8 & Isoferulic acid & $\mathrm{F}$ & 0.193 & 0.6 & 0.438 & 2.5 & 0.102 & 3.2 \\
\hline$\gamma$ & Isoleruitc acid & $\mathrm{C}$ & 28.441 & 88.3 & 10.401 & 59.4 & 0.360 & 11.3 \\
\hline 0 & nocoumoric ocid & $\mathrm{F}$ & 0.000 & 0.0 & 0.018 & 0.1 & 0.003 & 0.1 \\
\hline 9 & $p$-coumante aciu & $\mathrm{C}$ & 0.483 & 1.5 & 0.368 & 2.1 & 0.035 & 1.1 \\
\hline 10 & n bydroyvenzoic acid & $\mathrm{F}$ & 0.032 & 0.1 & 0.035 & 0.2 & 0.070 & 2.2 \\
\hline 10 & p-ily & $\mathrm{C}$ & 0.225 & 0.7 & 0.263 & 1.5 & 0.211 & 6.6 \\
\hline 11 & 3 4 dibydroyunbenylacetic acid & $\mathrm{F}$ & 0.000 & 0.0 & 0.000 & 0.0 & 0.000 & 0.0 \\
\hline 11 & 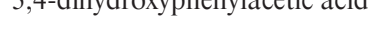 & $\mathrm{C}$ & 0.000 & 0.0 & 0.018 & 0.1 & 0.029 & 0.9 \\
\hline 12 & twanc cinnomic ocid & $\mathrm{F}$ & 0.000 & 0.0 & 0.053 & 0.3 & 0.086 & 2.7 \\
\hline 12 & mans-ciminamie acta & $\mathrm{C}$ & 0.097 & 0.3 & 0.053 & 0.3 & 0.587 & 18.4 \\
\hline Tota & content & & $32.21 \pm 0.01^{\mathrm{a}^{*}}$ & $100 \%$ & $17.51 \pm 0.01^{\mathrm{b} *}$ & $100 \%$ & $3.19 \pm 0.00^{*}$ & $100 \%$ \\
\hline & & & Flavo & & & & & \\
\hline 12 & Vitevin & $\mathrm{F}$ & 0.001 & 0.1 & 0.001 & 0.2 & 0.002 & 0.3 \\
\hline 13 & vileximl & $\mathrm{C}$ & 0.020 & 2.5 & 0.036 & 6.1 & 0.023 & 2.9 \\
\hline 14 & Putin & $\mathrm{F}$ & 0.001 & 0.1 & 0.001 & 0.1 & 0.002 & 0.3 \\
\hline 14 & KuntII & $\mathrm{C}$ & 0.017 & 2.1 & 0.013 & 2.2 & 0.037 & 4.6 \\
\hline 15 & Fnicatechin & $\mathrm{F}$ & 0.001 & 0.1 & 0.001 & 0.1 & 0.005 & 0.6 \\
\hline 15 & Epicalecnin & $\mathrm{C}$ & 0.253 & 31.3 & 0.202 & 34.1 & 0.034 & 4.2 \\
\hline 16 & Iuteolin & $\mathrm{F}$ & 0.000 & 0.0 & 0.000 & 0.0 & 0.002 & 0.2 \\
\hline 10 & Luteomint & $\mathrm{C}$ & 0.015 & 1.9 & 0.004 & 0.7 & 0.138 & 17.1 \\
\hline 17 & Ouercetin & $\mathrm{F}$ & 0.023 & 2.9 & 0.002 & 0.4 & 0.009 & 1.1 \\
\hline 11 & Queretint & $\mathrm{C}$ & 0.133 & 16.4 & 0.098 & 16.5 & 0.023 & 2.9 \\
\hline 18 & Anioenin & $\mathrm{F}$ & 0.008 & 1.0 & 0.008 & 1.4 & 0.015 & 1.9 \\
\hline 10 & Rpigentint & $\mathrm{C}$ & 0.121 & 14.9 & 0.153 & 25.8 & 0.135 & 16.8 \\
\hline 19 & Kaemnferol & $\mathrm{F}$ & 0.002 & 0.2 & 0.001 & 0.2 & 0.006 & 0.8 \\
\hline 13 & Racinpiciot & $\mathrm{C}$ & 0.192 & 23.7 & 0.036 & 6.0 & 0.161 & 20.0 \\
\hline 20 & Orientin & $\mathrm{F}$ & 0.000 & 0.0 & 0.002 & 0.3 & 0.021 & 2.6 \\
\hline 20 & Orientin & $\mathrm{C}$ & 0.022 & 2.7 & 0.035 & 5.9 & 0.191 & 23.7 \\
\hline Tota & content & & $0.81 \pm 0.00^{\mathrm{a} *}$ & $100 \%$ & $0.59 \pm 0.00^{\mathrm{b} *}$ & $100 \%$ & $0.81 \pm 0.00^{*}$ & $100 \%$ \\
\hline Tota & phenolics content & & $33.02 \pm 0.01^{a *}$ & & $18.10 \pm 0.01^{\mathrm{b*}}$ & & $4.00 \pm 0.00^{*}$ & \\
\hline
\end{tabular}

*Data are expressed as mean \pm SD $(n=3)$. Means in line related to a total content of phenolic acids, flavonoids and phenolics which characterized by the different letters are significantly different $(\mathrm{P}<0.05)$.

$\mathrm{F}$ - free forms of phenolic acids or flavonoids; $\mathrm{C}$ - conjugated forms of phenolic acids or flavonoids released from soluble esters and glycosides; $\mathrm{dm}$ - dry matter. 
beetroot matrix or that the hydrolysis process might have not been sufficiently effective. In contrast, the fermentation process decreased the contribution of the conjugated forms of syringic and isoferulic acids by $48.28 \%$ and $32.73 \%$ of total phenolic acids, respectively. Moreover, no changes were observed in the conjugated form of trans-cinnamic acid. The proportion of the free phenolic acids in fermented red beet juice was $12.9 \%(0.41 \pm 0.00 \mu \mathrm{g} / \mathrm{mL})$, while the proportion of the conjugated phenolic acids was $87.1 \%(2.78 \pm 0.00 \mu \mathrm{g} / \mathrm{mL})$. In general, the obtained results indicate that the fermentation process caused an increase in the proportion of free phenolic acids and reduced the proportion of conjugated phenolic acids in the phenolic acids profile. The proportion of free and bound phenolic acids in the fresh red beetroot is consistent with the results obtained by Mattila \& Hellström [2007]. In the cited study, phenolic acids in fresh and pickled red beetroot were found mainly in the bound form, however the pickling process caused an increase in the amount of free phenolic acids [Mattila \& Hellström, 2007]. Furthermore, according to our results, lactic acid fermentation caused different changes in the contents of the free and bound forms of hydroxybenzoic, hydroxycinnamic, and phenylacetic acid derivatives. As presented above, the lactic acid fermentation caused not only an increase in the content of the free forms of hydroxybenzoic, hydroxycinnamic, and phenylacetic acid derivatives, but also a decrease or no changes in the case of some compounds in fermented red beetroot. Similar observations were made for the conjugated forms. The same process not only reduced the content of the conjugated form of certain compounds but also, in some cases, caused an increase or did not show any effect on the content of other compounds. The results obtained in our study are in line with those obtained by Manach et al. [2004]. The cited authors reported that hydroxycinnamic acids frequently occurred in the form of simple esters with quinic acid or glucose in fruits and vegetables. In contrast, hydroxybenzoic acid derivatives have been shown to occur mainly in the form of glucosides, which reduces their availability to organisms. Fermentation is one of the food processes that increases the release of the conjugated phenolics, which was observed in our study [Shrestha et al., 2010; Hur et al., 2014; Huynh et al., 2014]. Research carried out by Değirmencioğlu et al. [2016] showed that microorganisms involved in the fermentation process had the ability to breakdown the food matrix, thereby releasing associated phytochemicals, which agrees with our data. However, the increased content of free phenolic acids may be related to $\beta$-glucosidase activity, an enzyme produced by microbial starter cultures that are used in the fermentation process. $\beta$-Glucosidase can release phenolic acids that are conjugated to sugars and glycosides by hydroxyl groups bound to cell-wall structural components. Breaking these bonds contributes to the release of conjugated phenolic acids by loosening the cell wall and thus increases the availability of phenolic acids in red beet products [Acosta-Estrada et al., 2014].

In the present study, the fresh roots were characterized by a statistically significantly $(\mathrm{P}<0.05)$ higher content of phenolic acids compared to the fermented roots (Table 2). The fermentation process of red beetroots led to a reduction in the total phenolic acids content by approximately $45.6 \%$.
Moreover, the total concentration of the phenolic acids in fermented beetroot juice was $3.19 \pm 0.00 \mu \mathrm{g} / \mathrm{mL}$. There are few available data on the total content of phenolic acids in fresh and fermented red beetroot. The results obtained in our study are consistent with these reported by Guldiken et al. [2016], according to which, the content of total phenolic acids in pickled red beetroot was $25 \%$ lower than that of fresh beetroot. According to Svensson et al. [2010], the reduction in the total content of phenolic acids after the fermentation process can be attributed to the activity of the phenolic acids' decarboxylases and reductases. Interestingly, Mattila \& Hellström [2007] observed that the pickling process did not seem to destroy phenolic acids in the product of red beetroots. However, in the case of fermented beetroot juice, the study carried out by Değirmencioğlu et al. [2016] showed that the total concentration of phenolic acids ranged from 34.35 to $59.91 \mu \mathrm{g} / \mathrm{mL}$, depending on the strain used for fermentation.

Another group of phenolic compounds identified in the red beet products were flavonoids, including vitexin, rutin, epicatechin, luteolin, quercetin, apigenin, kaempferol, and orientin (Table 1). Previously published data have shown the presence of flavonoids in red beetroot products. Georgiev et al. [2010] identified two flavonoids (catechin hydrate and epicatechin) in extracts from red beetroots. In contrast, Ben Haj Koubaier et al. [2014] showed that the stems of red beet contained four flavonoids (myricetin, quercetin, kaempferol and rutin), while no rutin was identified in the roots of red beetroot. In contrast, Székely et al. [2014] did not identify any flavonoids in the roots of different red beet cultivars. However, Rembiałkowska et al. [2011] identified six flavonoids (rutin, quercetin glycoside, quercetin, kaempferol, myricetin, and luteolin) in pickled red beetroot. Moreover, in the case of fermented red beetroot juice, Değirmencioğlu et al. [2016] identified ten flavonoids (myricetin, quercetin, kaempferol, rutin hydrate, naringenin, hesperidine, catechin, epicatechin, and epigallocatechin). Interestingly, completely different research results were obtained by Wruss et al. [2015]. They did not detect any flavonoids in juices prepared from seven beetroot varieties. The authors explain the lack of identified flavonoids in red beetroot juices by the low concentration of these compounds in the juices obtained compared to their concentration found in extracts prepared from dry matter samples. The different numbers of detected phenolics may be due to the use of different parts of the roots and may also depend on the species, variety, degree of maturity of the raw material, harvest period and storage conditions, as well as the vegetation season conditions [Wiczkowski et al., 2014; Sawicki et al., 2016].

In the samples of fresh and fermented red beets we tested, the dominant flavonoid was epicatechin $(34.4 \%$ and $34.1 \%$ of the total flavonoids content, respectively) (Table 2). Its content in fresh red beetroot was $0.254 \mu \mathrm{g} / \mathrm{g} \mathrm{dm}$, while in fermented beetroot it was $0.203 \mu \mathrm{g} / \mathrm{g} \mathrm{dm}$. The second major compound among the flavonoids in the fresh roots analyzed was kaempferol $(0.194 \mu \mathrm{g} / \mathrm{g} \mathrm{dm})$, which accounted for $23.9 \%$ of the total flavonoids. In the fresh red beetroot, we detected a much higher content of quercetin $(0.156 \mu \mathrm{g} / \mathrm{g} \mathrm{dm})$ and apigenin $(0.129 \mu \mathrm{g} / \mathrm{g} \mathrm{dm})$ than in the fermented beetroot, which accounted for $19.3 \%$ and $15.9 \%$ of total flavonoids, respective- 
ly. The fresh red beetroot had also the lowest content of luteolin $(0.015 \mu \mathrm{g} / \mathrm{g} \mathrm{dm})$. In addition, in the fermented red beetroot, apigenin $(0.161 \mu \mathrm{g} / \mathrm{g} \mathrm{dm})$ was the second major compound, followed by quercetin $(0.100 \mu \mathrm{g} / \mathrm{g} \mathrm{dm})$. A much lower content, compared to that of luteolin, apigenin, and quercetin in fermented red beetroot, was detected for vitexin $(0.037 \mu \mathrm{g} / \mathrm{g} \mathrm{dm})$, kaempferol $(0.037 \mu \mathrm{g} / \mathrm{g} \mathrm{dm})$, orientin $(0.037 \mu \mathrm{g} / \mathrm{g} \mathrm{dm})$, and rutin $(0.014 \mu \mathrm{g} / \mathrm{g} \mathrm{dm})$. Likewise in the fresh roots, luteolin also occurred in the lowest amount $(0.004 \mu \mathrm{g} / \mathrm{g} \mathrm{dm})$ in the fermented roots. In contrast with the fresh and fermented red beetroots, the main flavonoid analyzed in the fermented red beetroot juice was orientin. The total concentration of orientin was $0.212 \mu \mathrm{g} / \mathrm{mL}$ (26.3\% of the total flavonoids in the fermented red beetroot juice). In addition, kaempferol $(0.167 \mu \mathrm{g} / \mathrm{mL})$

was the second major compound, followed by apigenin $(0.150 \mu \mathrm{g} / \mathrm{mL})$ and luteolin $(0.140 \mu \mathrm{g} / \mathrm{mL})$. Lower concentrations of rutin $(0.039 \mu \mathrm{g} / \mathrm{mL})$, epicatechin $(0.039 \mu \mathrm{g} / \mathrm{mL})$, and quercetin $(0.032 \mu \mathrm{g} / \mathrm{mL})$ were determined in red beet juice, with the lowest concentration being that of vitexin $(0.025 \mu \mathrm{g} / \mathrm{mL})$. Our data differ from those reported in the literature. For instance, Georgiev et al. [2010] reported catechin hydrate to be the major flavonoid in extracts from red beetroot, whereas Ben Haj Koubaier et al. [2014] showed that kaempferol was the dominant flavonoid in the roots of red beet, while quercetin in the stems. Moreover, research carried out by Kazimierczak et al. [2014] showed that quercetin was the main flavonoid that occurred in fresh red beetroot. In the case of fermented beet juice, the results are also variable. Research carried out by Kazimierczak et al. [2014] showed quercetin-3-O-glucoside to be the major flavonoid of fermented beetroot juice, while Değirmencioğlu et al. [2016] found catechin and myricetin to be the dominant flavonoids in beetroot juice fermented by Saccharomyces cerevisiae and Saccharomyces boulardii.

The fermentation process caused a reduction in the total content of free form of flavonoids and an increase in their conjugated form. The total content of free flavonoids in fresh red beet was at $0.04 \pm 0.00 \mu \mathrm{g} / \mathrm{g} \mathrm{dm}(4.4 \%$ of the total flavonoids content), while after the fermentation process it decreased to $0.02 \pm 0.00 \mu \mathrm{g} / \mathrm{g} \mathrm{dm}(2.7 \%$ of the total flavonoids content). In contrast, the total content of conjugated flavonoids in fresh red beet was at $0.77 \pm 0.00 \mu \mathrm{g} / \mathrm{g} \mathrm{dm}(95.6 \%$ of the total flavonoids content), while after the fermentation process it was $0.57 \pm 0.00 \mu \mathrm{g} / \mathrm{g} \mathrm{dm}(97.3 \%$ of the total flavonoids content). However, the same process not only reduced the content of the free form of certain compounds but also, in some cases, caused a decrease or did not show any effect on the content of other compounds. As presented in Table 2, the application of the fermentation process caused a decrease in the content of the free form of quercetin, and an increase in the content of the free form of apigenin. In addition, no changes were observed in the contents of free epicatechin, luteolin, or kaempferol. It was also found that the fermentation process increased the concentration of vitexin and orientin while caused no changes in rutin concentration. For the conjugated forms of flavonoids, the fermentation process caused an increase in the content of rutin, epicatechin, and quercetin. At the same time, it decreased contents of the conjugated form of luteolin and kaempferol. In the case of the fermented red beetroot juice, the proportion of free flavonoids was $7.8 \%$
$(0.06 \pm 0.00 \mu \mathrm{g} / \mathrm{mL})$, while the proportion of conjugated flavonoids was $92.2 \%(0.75 \pm 0.00 \mu \mathrm{g} / \mathrm{mL})$. The results obtained show that fresh and fermented beetroot can be a good source of flavonoids in an everyday diet. In contrast to phenolic acids, the application of the fermentation process decreased the amount of free flavonoids. Likewise for phenolic acids, the fermentation process may affect the ester and glycosidic bonds and thus can contribute to changes in the content of flavonoids by releasing them from being bound to the insoluble cell wall material [Svensson et al., 2010]. It may be surprising that the conjugated forms of rutin, vitexin, and orientin were found in fermented beet products, as they ought to be hydrolyzed in the fermentation process. This might be explained by the fact that $\mathrm{C}$-glucosides of phenolics do not undergo hydrolysis during fermentation. In the case of rutin, similarly to chlorogenic acid, its presence in the analyzed material after hydrolysis may be associated with the loosening of the red beetroot matrix and releasing this compound from larger structures it was incorporated into. Changes in the profile of the flavonoids during fermentation are mainly due to the activity of enzymes produced by a huge variety of microflora, often uncharacterized. As a result of the activity of the cellulolytic, ligninolytic, and pectinolytic enzymes, the cell walls of the food matrix can be completely ruptured by the hydrolysis of ester bonds, resulting in oxidative degradation of the matrix and release of the bound flavonoids [Huynh et al., 2014]. However, it should be noted that the fermentation process does not always result in an increase in phytochemicals content due to the loosening of the food matrix, but can also cause a decrease in content of certain components. Phytochemicals could be metabolized (e.g., deglycosylated) into other low molecular forms [Aura et al., 2002]. In general, the potential of lactic acid bacteria to metabolize secondary plant compounds remains unknown. Therefore, further research in this field is needed to elucidate the microbiological pathways for phytochemical conversion, metabolite identification, and biological activity determination.

As in the case of phenolic acids, the richest source of flavonoids turned out to be the fresh roots, which contained $0.81 \pm 0.00 \mu \mathrm{g}$ flavonoids $/ \mathrm{g} \mathrm{dm}$. A lower by approximately $27.2 \%$ total flavonoids content was observed in the fermented red beetroot. However, the commercial fermented beetroot juice contained $0.81 \pm 0.00 \mu \mathrm{g}$ flavonoids $/ \mathrm{mL}$. As with the content of phenolic acids, our data for flavonoids differed from those available in the literature, which may be related to the fact that the authors of the publications have expressed the results per beetroot dry extracts [Georgiev et al., 2010; Čanadanović-Brunet et al., 2011; Ben Haj Koubaier et al., 2014]. On the other hand, Kazimierczak et al. [2014] compared the profile of flavonoids in fermented beetroot juices from organic versus conventional production. Interestingly, they did not notice any significant differences in the content of flavonoids between the studied materials. As mentioned for phenolic acids, the differences in the total content of flavonoid compounds between results obtained in this study and the results from the cited papers may have been due to the use of different beetroot varieties. The impact of the variety, as well as the growing conditions, growing season, and the method 
and length of storage on the level of various phytochemicals in vegetables was demonstrated in earlier works [Wiczkowski \& Piskuła, 2004; Sawicki \& Wiczkowski, 2018]. Moreover, the type of microorganisms used in the fermentation process as well as its conditions and duration could play a key role in the total content of flavonoids [Shrestha et al., 2010].

\section{Total contents of phenolic acids and flavonoids in red beetroot products}

Based on the results of HPLC-MS/MS analysis, the fresh roots were shown to be the richest source of phenolics. The total phenolics content in fresh red beet was $33.02 \pm 0.01 \mu \mathrm{g} / \mathrm{g} \mathrm{dm}$, while in the fermented beetroot, it was $18.10 \pm 0.01 \mu \mathrm{g} / \mathrm{g} \mathrm{dm}$. In contrast, in commercial red beet juice it was as low as $4.00 \pm 0.00 \mu \mathrm{g} / \mathrm{mL}$. Our data differ from those available in the literature [Vulić et al., 2014; Ben Haj Koubaier et al., 2014; Wruss et al., 2015; Guiné et al., 2018]. It is important to note, however, that the most common method for determining total phenolics content is the Folin-Ciocalteau method rather than the HPLC-MS method, which is not an absolute measurement of the amount of phenolics in a tested sample. Some substances contained in the sample studied, including organic acids, residual sugars, amino acids, proteins and other hydrophilic compounds, interfere with this test. Thus, the results achieved for the samples tested can differ significantly, which was also the case in the studies presented above. Therefore, detailed identification and quantification of phenolic compounds are essential.

Moreover, it should be noted that the 14-day spontaneous fermentation process resulted in a significant reduction of the total content of phenolics by $45.18 \%$. Results of our research are consistent with the findings reported by Hunaefi et al. [2013], who observed that the total phenolics content increased slightly until day seven of the fermentation process and successively decreased for a longer time of fermentation. Hunaefi et al. [2013] and Rodríguez et al. [2008] explain that the reduction in total phenolics content may be due to an increase in the amounts of lactic acid bacteria. There is evidence that lactic acid bacteria are involved in the metabolism of dietary phenolics, i.e. their cause their degradation and thus positively affect the final product, imparting it a characteristic taste, aroma, and texture.

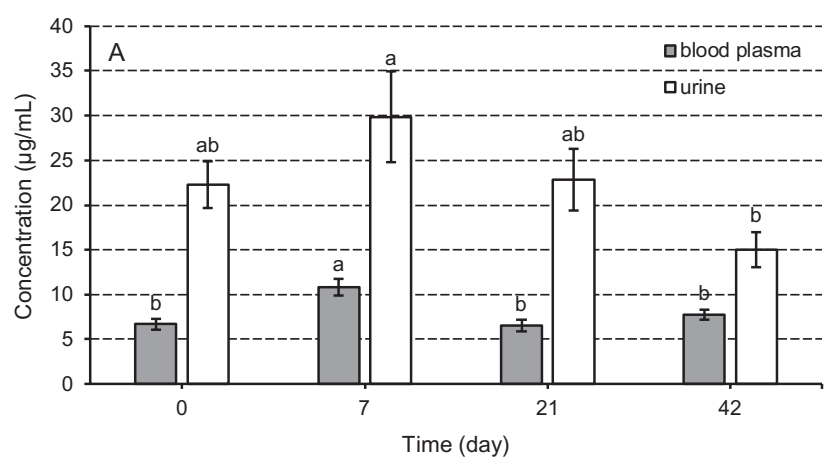

In the case of fermented beet juice, it is important to pay attention to the food processing, which usually consists of the pre-treatment, including cleaning, rinsing and slicing, and the basic treatment involving thermal food processing. Treatments applied in the food processing are aimed at eliminating unwanted impurities, microbes, non-nutrients, inactivating enzymes; and also at increasing the digestibility and availability of nutrients; at improving the structure and consistency of a food product; and finally at ensuring its appropriate organoleptic characteristics. On the other hand, these treatments can have a destructive effect on health-promoting ingredients, causing their losses at every stage of processing [Ravichandran et al., 2013; Wiczkowski et al., 2015].

\section{Content of phenolic acids and flavonoids in blood plasma and urine of volunteers consuming fermented beetroot juice}

To the best of our knowledge, this is the first study that has characterized the profile of phenolic acids and flavonoids in human body fluids after long-term and regular consumption of red beetroot juice. Sixteen compounds, including four hydroxybenzoic acid derivatives (protocatechuic, $m$-hydroxybenzoic, syringic, and $p$-hydroxybenzoic acids), six hydroxycinnamic acid derivatives (chlorogenic, caffeic, sinapic, ferulic, $p$-coumaric, and trans-cinnamic acids), one phenylacetic acid derivative (3,4-dihydroxyhydrophenylacetic acid), and five flavonoids (epicatechin, luteolin, quercetin, apigenin and kaempferol) were identified in the blood plasma and urine samples before and after the intake of fermented red beetroot juice (Table 1). All the identified compounds were also detected in the material tested (red beet juice). However, isoferulic acid, vitexin, rutin, and orientin, which were found in the consumed commercial fermented red beet juice, were not identified in the samples of human body fluids.

Before and after regular consumption of fermented beetroot juice, phenolic acids and flavonoids appeared in blood plasma and urine throughout the forty-two days of the experiment (Figure 1). The total concentration of phenolic acids in the volunteers' blood plasma before drinking fermented beetroot juice was $6.68 \pm 0.59 \mu \mathrm{g} / \mathrm{mL}$ and increased to $10.84 \pm 0.92 \mu \mathrm{g} / \mathrm{mL}$ after seven days of regular juice intake. Afterwards, it decreased slightly to $6.51 \pm 0.67 \mu \mathrm{g} / \mathrm{mL}$ after

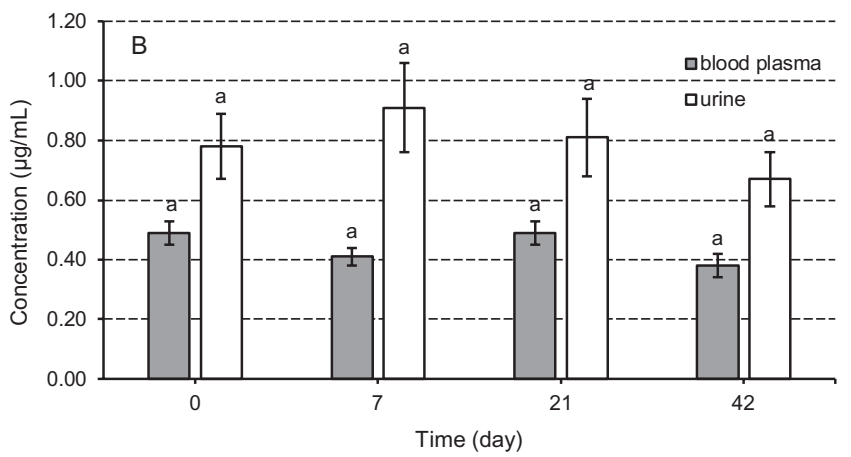

FIGURE 1. Concentration of phenolic acids (A) and flavonoids (B) in blood plasma and urine of volunteers after the intake of fermented beetroot juice for a period of 42 days.

Values are mean $\pm \mathrm{SD}(\mathrm{n}=24)$. Means related to a total content of phenolic acids or flavonoids marked by different letter above bars are significantly different $(\mathrm{P}<0.05)$. 
twenty-one days and then increased again to $7.75 \pm 0.55 \mu \mathrm{g} /$ $\mathrm{mL}$ after forty-two days of regular intake of the juice. An increase in the total concentration of phenolic acids $(\mathrm{P}<0.05)$ was noted as soon as after seven days of regular consumption of fermented beetroot juice. Differences in the total concentration of flavonoids in blood plasma were not found to be statistically significant $(\mathrm{P} \geq 0.05)$ before $(0.49 \pm 0.04 \mu \mathrm{g} / \mathrm{mL})$ and after seven $(0.41 \pm 0.03 \mu \mathrm{g} / \mathrm{mL})$, twenty-one $(0.49 \pm 0.04 \mu \mathrm{g} / \mathrm{mL})$, and forty-two $(0.38 \pm 0.04 \mu \mathrm{g} / \mathrm{mL})$ days of regular consumption of juice from red beetroot. Furthermore, urine analysis of the volunteers before the intake of fermented beetroot showed that the total concentration of phenolic acids was at $22.28 \pm 2.65 \mu \mathrm{g} / \mathrm{mL}$. After forty-two days of consumption of fermented beetroot juice, as in the case of blood plasma, the total concentration of phenolic acids in the urine did not change statistically significantly ( $\mathrm{P} \geq 0.05$ ). Regular intake of fermented beetroot juice for seven days has resulted in a slight increase in the total concentration of phenolic acid. Total urinary excretion of flavonoids has not changed statistically $(\mathrm{P} \geq 0.05)$ throughout the entire forty-two day long period of fermented beetroot juice intake. Before starting the regular consumption of fermented beetroot juice, the total concentration of flavonoids in the urine of volunteers was at $0.78 \pm 0.11 \mu \mathrm{g} / \mathrm{mL}$. After seven days, it increased to $0.91 \pm 0.15 \mu \mathrm{g} / \mathrm{mL}$, and afterwards decreased to $0.81 \pm 0.13 \mu \mathrm{g} / \mathrm{mL}$ after twenty-one days and to $0.67 \pm 0.09 \mu \mathrm{g} / \mathrm{mL}$ after forty-two days. It was found that after forty-two days of consumption of fermented beetroot juice by the volunteers, the total plasma and urine concentrations of phenolic acids and flavonoids did not change compared to those determined in volunteers' fluids before starting the regular consumption of juice. To the best of our knowledge, limited data are available on the bioavailability of phenolics after long-term ingestion.

The factor affecting the bioavailability of phenolics is the nature of the food matrix itself. Phenolics can react with food ingredients, e.g., some proteins and carbohydrates, which can significantly affect their absorption from digestion. Other important factors are the intestinal environment, such as the $\mathrm{pH}$ or the presence of bile salts [Manach et al., 2004]. Interindividual variability, and more specifically, differences in the intestinal microflora of volunteers, may affect the bioavailability of phenolic acids and flavonoids as well. Research conducted by Aura et al. [2002], van't Slot \& Humpf [2009], and Gonthier et al. [2003] showed a successive postprandial appearance of microbial phenolic metabolites in plasma after $0.5-4 \mathrm{~h}$. Moreover, a study conducted by Feliciano et al. [2016] showed ingestion of foods rich in polyphenols to result in an increase in the concentration of phenolic acids in plasma compared to that on the first day of the intervention. According to the aforementioned reports, flavonoids are degraded during digestive processes, resulting in phenolic acids formation and thus decreasing the concentration of flavonoids. Unfortunately, we did not notice this correlation in our study. Additionally, the bioavailability of phenolic compounds may be limited due to the interactions with their transporters. In addition, we cannot exclude the possibility of phenolic acids and flavonoids distribution and accumulation in other tissues. Another explanation for such an insignificant variation in plasma levels of phenolic acids and flavonoids is that al- though the diets were controlled, the subjects followed the dietary instructions well (exclusion of foods rich in betalains) but did not eat exactly the same amounts of polyphenols-rich fruits and vegetables. Interestingly, the research conducted by Moon et al. [2000] showed that the long-term consumption of foods rich in flavonoids did not cause the accumulation of significant amounts of flavonoids in the plasma. It should be noted, however, that despite a number of studies that have been carried out, there is not enough data on phenolic acids and flavonoids in human tissues. Previous studies have indicated that despite the low absorption of phenolic acids and flavonoids, these compounds are extensively metabolized in the gut and liver [Marín et al., 2015]. A number of chemical processes change the physical properties of phenolics, making them more soluble in water. Moreover, the observed insignificant variability of the urinary excretion of these compounds after forty-two days of consumption of fermented beetroot juice suggests that the majority of the phenolic acids and flavonoids supplied with juice have been metabolized by the intestinal microflora to smaller low molecular weight metabolites. Generally, phenolic acids and flavonoids are rapidly excreted with urine, indicating that the daily consumption of plant products is necessary to maintain high blood metabolite levels. All things considered, it should be noted that the bioavailability of plant phenolic acids and flavonoids may be affected by internal factors (including age, sex, ethnicity, disease and genetic polymorphisms) and external factors (including doses, food matrix, and eating habits).

Summarizing, our results showed that forty-two days of consumption of a commercial fermented beetroot juice did not affect the concentration of phenolic acids and flavonoids in plasma and urine of the volunteers. In turn, Sawicki et al. [2018] observed that the long-term and regular consumption of the red beet juice caused stabilization of both the profile and content of betalains in the physiological fluids of volunteers. Irregular changes in the phenolic acid and flavonoid profiles in human plasma and urine, in contrast to the profile and content of betalains, may be due to the low concentration of phenolic acids $(3.19 \pm 0.00 \mu \mathrm{g} / \mathrm{mL})$ and flavonoids $(0.81 \pm 0.00 \mu \mathrm{g} / \mathrm{mL})$ (Table 1$)$ and a high concentration of betalains $(0.21 \pm 0.00 \mathrm{~g} / \mathrm{mL})$ in beetroot juice [Sawicki et al., 2018]. In addition to beetroot juice, volunteers consumed a number of foods that are rich sources of phenolic acids and flavonoids. Taking into consideration that the estimated daily intake of phenolic compounds by the Polish population was $1756.5 \pm 695.8 \mathrm{mg} /$ day [Grosso et al., 2014], it seems difficult to assume that such a small contribution to the daily intake of phenolic compounds as $200 \mathrm{~mL}$ of beetroot juice (i.e. $0.8 \mathrm{mg}$, being not even $0.1 \%$ of daily intake) will significantly affect levels of metabolites in human fluids.

\section{CONCLUSIONS}

To the best of our knowledge, this is the first time when the effects of fermentation on the profile and content of red beet phenolic acids and flavonoids have been determined as well as when the impact of the long-term and regular consumption of this vegetable on the profile and content of phenolics in plasma and urine of volunteers has been established. 
Our research has shown that red beet and its products are notable source of phenolic acids and flavonoids. The analyses performed have revealed that isoferulic acid, protocatechuic acid, epicatechin, and apigenin predominated among the twenty compounds detected in beetroot and its products. Furthermore, the total content of phenolic acids and flavonoids differed significantly between the red beet products studied. The fermentation process simultaneously increased contents of free phenolic acids and conjugated flavonoids as well as decreased contents of conjugated phenolic acids and free flavonoids. However, our results showed that the long-term and regular consumption of fermented beetroot juice generally did not affect the concentration of phenolics in plasma and urine of the volunteers. From the physiological and nutritional points of view, information on the full profile of red beet phenolic acids and flavonoids is very important because it may help predict their biological activity. Moreover, further studies are now needed to determine how red beetroot phytochemicals, including phenolic acids and flavonoids, behave under the conditions of other food processing treatments and upon consumption of other red beet products (influence of the food matrix).

\section{RESEARCH FUNDING}

This research was supported by the statutory funds of the Department of Chemistry and Biodynamics of Food of the Institute of Animal Reproduction and Food Research of the Polish Academy of Sciences in Olsztyn, Poland.

\section{CONFLICT OF INTERESTS}

All authors declare no conflict of interests.

\section{REFERENCES}

1. Acosta-Estrada, B.A., Gutiérrez-Uribe, J.A., Serna-Saldívar, S.O. (2014). Bound phenolics in foods: A review. Food Chemistry, 152, 46-55.

2. Aura, A.M., O’Leary, K.A., Williamson, G., Ojala, M., Bailey, M., Puupponen-Pimiä, R., Nuutila, A.M., Oksman-Caldentey, K.M., Poutanen, K. (2002). Quercetin derivatives are deconjugated and converted to hydroxyphenylacetic acids but not methylated by human fecal flora in vitro. Journal of Agricultural and Food Chemistry, 50(6), 1725-1730.

3. Ben Haj Koubaier, H., Snoussi, A., Essaidi, I., Chaabouni, M.M., Thonart, P., Bouzouita, N. (2014). Betalain and phenolic compositions, antioxidant activity of Tunisian red beet (Beta vulgaris L. conditiva) roots and stems extracts. International Journal of Food Properties, 17, 1934-1945.

4. Čanadanović-Brunet, J.M., Savatović, S.S., Ćtković, G.S., Vulić, J., Djilas, S., Sinisa, M., Cvetković, D.D. (2011). Antioxidant and antimicrobial activities of beet root pomace extracts. Czech Journal of Food Sciences, 29(6), 575-585.

5. Carrillo, C., Rey, R., Hendrickx, M., Del Mar Cavia, M., Alonso-Torre, S. (2017). Antioxidant capacity of beetroot: traditional vs novel approaches. Plant Foods for Human Nutrition, 72(3), 266-273.
6. Chhikara, N., Kushwaha, K., Sharma, P., Gat, Y., Panghal, A. (2019). Bioactive compounds of beetroot and utilization in food processing industry: A critical review. Food Chemistry, 272, 192-200.

7. Clifford, T., Howatson, G., West, D.J., Stevenson, E.J. (2015). The potential benefits of red beetroot supplementation in health and disease. Nutrients, 7(4), 2801-2822.

8. Değirmencioğlu, N., Gurbuz, O., Şahan, Y. (2016). The monitoring, via an in vitro digestion system, of the bioactive content of vegetable juice fermented with Saccharomyces cerevisiae and Saccharomyces boulardii. Journal of Food Processing and Preservation, 40(4), 798-811.

9. Feliciano, R.P., Istas, G., Heiss, C., Rodriguez-Mateos, A. (2016). Plasma and urinary phenolic profiles after acute and repetitive intake of wild blueberry. Molecules, 21(9), art. no. 1120.

10. Guiné, R.P.F., Gonçalves, F., Lerat, C., Idrissi, T.E., Rodrigi, E., Correia, P.M.R., Gonçalves, J.C. (2018). Extraction of phenolic compounds with antioxidant activity from beetroot (Beta vulgaris L.). Current Nutrition \& Food Science, 14(4), 350-357.

11. Georgiev, V.G., Weber, J., Kneschke, E.M., Denev, P.N., Bley, T., Pavlov, A.I. (2010). Antioxidant activity and phenolic content of betalain extracts from intact plants and hairy root cultures of the red beetroot Beta vulgaris cv. Detroit dark red. Plant Foods for Human Nutrition, 65(2), 105-111.

12. Gonthier, M.P., Donovan, J.L., Texier, O., Felgines, C., Remesy, C., Scalbert, A. (2003). Metabolism of dietary procyanidins in rats. Free Radical Biology \& Medicine, 35(8), 837-844.

13. Grosso, G., Stepaniak, U., Topor-Mądry, R., Szafraniec, K., Pająk, A. (2014). Estimated dietary intake and major food sources of polyphenols in the Polish arm of the HAPIEE study. Nutrition, 30(11-12), 1398-403.

14. Guldiken, B., Toydemir, G., Nur Memis, K., Okur, S., Boyacioglu, D., Capanoglu, E. (2016). Home-processed red beetroot (Beta vulgaris L.) products: changes in antioxidant properties and bioaccessibility. International Journal of Molecular Sciences, 17(6), art. no. 858.

15. Hasan, M.N., Sultan, M.Z., Mar-E-Um, M. (2014). Significance of fermented food in nutrition and food science. Journal of Scientific Research, 6(2), 373-386.

16. Hunaefi, D., Akumo, D.N., Smetanska, I. (2013). Effect of fermentation on antioxidant properties of red cabbages. Food Biotechnology, 27(1), 66-85.

17. Hur, S.J., Lee, S.Y., Kim, Y.C., Choi, I., Kim, G.B. (2014). Effect of fermentation on the antioxidant activity in plant-based foods. Food Chemistry, 1(160), 346-356.

18. Huynh, N.T., Van Camp, J., Smagghe, G., Raes, K. (2014). Improved release and metabolism of flavonoids by steered fermentation processes: a review. International Journal of Molecular Sciences, 15(11), 19369-19388.

19. Kazimierczak, R., Hallmann, E., Lipowski, J., Drela, N., Kowalik, A., Püssa, T., Matt, D., Luik, A., Gozdowski, D., Rembiałkowska, E. (2014). Beetroot (Beta vulgaris L.) and naturally fermented beetroot juices from organic and conventional production: metabolomics, antioxidant levels and anticancer activity. Journal of the Science of Food and Agriculture, 94(3), 2618-2629.

20. Manach, C., Scalbert, A., Morand, C., Rémésy, C., Jiménez, L. (2004). Polyphenols: food sources and bioavailability. The American Journal of Clinical Nutrition, 79(5), 727-747. 
21. Mattila, P., Hellström, J. (2007). Phenolic acids in potatoes, vegetables, and some of their products. Journal of Food Composition and Analysis, 20(3-4), 152-160.

22. Marín, L., Miguélez, E.M., Villar, C.J., Lombó, F. (2015). Bioavailability of dietary polyphenols and gut microbiota metabolism: antimicrobial properties. BioMed Research International, 2015, art. no. 905215.

23. Moon, J.H., Nakata, R., Oshima, S., Inakuma, T., Terao, J. (2000). Accumulation of quercetin conjugates in blood plasma after the short-term ingestion of onion by women. American Journal of Physiology Regulatory, Integrative, Comparative, Physiology, 279(2), R461-R467.

24. Pandey, K.B., Rizvi, S.I. (2009). Plant polyphenols as dietary antioxidants in human health and disease. Oxidative Medicine and Cellular Longevity, 2(5), 270-278.

25. Raikos, V., McDonagh, A., Ranawana, V., Duthie, G. (2016). Processed beetroot (Beta vulgaris L.) as a natural antioxidant in mayonnaise: effects on physical stability, texture and sensory attributes. Food Science and Human Wellness, 5(4), 191-198.

26. Ravichandran, K., Ahmed, A.R., Knorr, D., Smetanska, I. (2012). The effect of different processing methods on phenolic acid content and antioxidant activity of red beet. Food Research International, 48(1), 16-20.

27. Ravichandran, K., Saw T.M.M.N., Mohdaly A.A.A., Gabr, M.M.A., Kastell, A., Riedel, H., Cai, Z., Knorr, D., Smetanska, I. (2013). Impact of processing of red beet on betalain content and antioxidant activity. Food Research International, 50, 670-675.

28. Rein, M.J., Renouf, M., Cruz-Hernandez, C., Actis-Goretta, L., Thakkar, S.K., da Silva Pinto, M. (2013). Bioavailability of bioactive food compounds: a challenging journey to bioefficacy. British Journal of Clinical Pharmacology, 75(3), 588-602.

29. Rembiałkowska, M.E., Hallmann, E., Kazimierczak, R., Skąpska, W., Ardasińska, B. (2011). Ecological methods for fruit and vegetables processing considering health-promoting properties of the finished products. [http://www.up.lublin.pl/files/foodscience/2014_newsy/11/2014.11.19_kombucha.pdf], (11,2014) (in Polish).

30. Rodríguez, H., Landete, J.M., Rivas, B. de las, Muñoz, R. (2008). Metabolism of food phenolic acids by Lactobacillus plantarum CECT 748T. Food Chemistry, 107(4), 1393-1398.

31. Sawicki, T., Bączek, N., Wiczkowski, W. (2016). Betalain profile, content and antioxidant capacity of red beetroot dependent on the genotype and root part. Journal of Functional Foods, 27, 249-261.

32. Sawicki, T., Topolska, J., Romaszko, E., Wiczkowski, W. (2018). Profile and content of betalains in plasma and urine of volunteers after long-term exposure to fermented red beet juice. Journal of Agricultural and Food Chemistry, 66(16), 4155-4163.

33. Sawicki, T., Wiczkowski, W. (2018). The effects of boiling and fermentation on betalain profiles and antioxidant capacities of red beetroot products. Food Chemistry, 259, 292-303.
34. Saxena, M., Saxena, J., Pradhan, A. (2012). Flavonoids and phenolic acids as antioxidants in plants and human health. International Journal of Pharmaceutical Sciences Review and Research, 16(2), 130-134.

35. Shrestha, A.K., Dahal, N.R., Ndungutse, V. (2010). Bacillus fermentation of soybean: a review. Journal of Food Science and Technology, 6, 1-9.

36. Svensson, L., Sekwati-Monang, B., Lutz, D.L., Schieber, A., Gänzle, M.G. (2010). Phenolic acids and flavonoids in nonfermented and fermented red sorghum (Sorghum bicolor (L.) Moench). Journal of Agricultural and Food Chemistry, 58(16), 9214-9220.

37. Székely, D., Szalóki-Dorkó, L., Stéger-Máté, M., Szabó-Nótin, B., Ivanics, J., Monspart-Sényi, J. (2014). Distribution of antioxidant components in roots of different red beets (Beta vulgaris L.) cultivars. Acta Alimentaria, 43, 164-171.

38. van't Slot, G., Humpf, H.U. (2009). Degradation and metabolism of catechin, epigallocatechin-3-gallate (EGCG), and related compounds by the intestinal microbiota in the pig cecum model. Journal of Agricultural and Food Chemistry, 57(17), 8041-8048.

39. Vulić, J.J., Ćebović, T.N., Čanadanović-Brunet, J.M., Ćtković, G.S., Čanadanović, V.M., Djilas, S.M., Tumbas Šaponjac, V.T. (2014). In vivo and in vitro antioxidant effects of beetroot pomace extracts. Journal of Functional Foods, 6, 168-175.

40. Wiczkowski, W., Piskuła, M.K. (2004). Food flavonoids. Polish Journal of Food and Nutrition Sciences, 13(54), 101-114.

41. Wiczkowski, W., Romaszko, J., Bucinski, A., Szawara-Nowak, D., Honke, J., Zielinski, H., Piskula, M.K. (2008). Quercetin from shallots (Allium cepa L. var. aggregatum) is more bioavailable than its glucosides. The Journal of Nutrition, 138(5), 885-888.

42. Wiczkowski, W., Szawara-Nowak, D., Topolska, J. (2015). Changes in the content and composition of anthocyanins in red cabbage and its antioxidant capacity during fermentation, storage and stewing. Food Chemistry, 167, 115-123.

43. Wiczkowski, W., Szawara-Nowak, D., Sawicki, T., Mitrus, J., Kasprzykowski, Z., Horbowicz, M. (2016). Profile of phenolic acids and antioxidant capacity in organs of common buckwheat sprout. Acta Alimentaria, 45(2), 250-257.

44. Wiczkowski, W., Topolska, J., Honke, J. (2014). Anthocyanins profile and antioxidant capacity of red cabbages are influenced by genotype and vegetation period. Journal of Functional Foods, 7(1), 201-211.

45. Wruss, J., Waldenberger, G., Huemer, S., Uygun, P., Lanzerstorfer, P., Müller, U., Höglinger, O., Weghuber, J. (2015). Compositional characteristics of commercial beetroot products and beetroot juice prepared from seven beetroot varieties grown in Upper Austria. Journal of Food Composition and Analysis, 42, 46-55.

Submitted: 3 October 2019. Revised: 4 December 2019 and 14 January 2020. Accepted: 15 January 2020. Published on-line: 7 February 2020. 